\title{
O PROJETO ESTUDO DO MEIO EM PONTA GROSSA (PARANÁ, BRASIL) E A REALIZAÇÃO DE ROTEIROS TURÍSTICO-PEDAGÓGICOS VOLTADOS PARA OS ASPECTOS DA GEODIVERSIDADE
}

\section{The "study of the environment" project in Ponta Grossa (Paraná State, Brazil) and the effectiveness of educational tours involving aspects of geodiversity}

\author{
Jasmine Cardozo Moreira ${ }^{1}$ - Maricy Cardozo Teixeira Pinto ${ }^{2 \dagger}$
}

\begin{abstract}
Resumo: O Projeto Estudo do Meio foi um projeto transdisciplinar destinado aos professores do ensino público Fundamental e infantil, realizado entre 2007 e 2012, que teve como objetivo a educação patrimonial, englobando o patrimônio natural. Com o intuito de oferecer, aos professores, a oportunidade de conhecerem e debaterem sobre o meio, foram organizadas saídas de campo para atrativos turísticos. Assim, este artigo teve por objetivo analisar, sob a ótica do professor, a participação neste projeto e o interesse na realização de roteiros turístico-pedagógicos envolvendo aspectos da geodiversidade. A metodologia englobou: a participação nas saídas de campo, pesquisas bibliográficas e aplicação de questionários. Observou-se a importância da formação continuada tendo como objetivo agregar conhecimentos que contribuam para a construção de uma consciência conservacionista dos professores. Concluindo, foi demonstrado que, para $98 \%$ dos professores entrevistados, a região apresenta potencial para a realização do Geoturismo e de roteiros turísticos voltados para aspectos da geodiversidade.
\end{abstract}

Palavras-chave: Formação de professores. Ensino Fundamental. Educação ambiental. Geodiversidade.

\begin{abstract}
The Study of the Environment Project is an interdisciplinary project for primary school teachers, developed between 2007 and 2012, which concerns heritage education, encompassing the natural heritage. In order to give teachers the opportunity to meet and discuss about the environment, organized field trips to different tourist attractions were organised. This article aims to analyze the perspective of the teacher, participation in this project and interest in conducting educational tours involving aspects of geodiversity. The methodology involved field trips, bibliographic research and questionnaires. We observed the importance of continuing education with the objective of gaining new knowledge contributing to the construction of conservationist teachers. In conclusion, this study found that for $98 \%$ of surveyed teachers the region has potential to carry out the Geotourism and tours focused on aspects of geodiversity.
\end{abstract}

Keywords: Teacher training. Elementary school. Environmental education. Geodiversity.

\footnotetext{
${ }^{1}$ Universidade Estadual de Ponta Grossa, Departamento de Turismo, Praça Santos de Andrade, s/n, Centro, CEP 84100-000, Ponta Grossa, PR, Brasil. E-mail: <jasminecardozo@gmail.com>

${ }^{2}$ Prefeitura Municipal de Ponta Grossa, Secretaria Municipal de Educação, Ponta Grossa, PR, Brasil. ${ }^{\dagger}$ In memoriam.
} 


\section{Introdução}

Ponta Grossa é um município do Estado do Paraná, que possui diversos atrativos turísticos ligados ao seu patrimônio natural. Por intermédio da Secretaria Municipal de Educação, entre 2007 e 2012, desenvolveu o Projeto Estudo do Meio, um projeto envolvendo diversas disciplinas, destinado aos professores do ensino público Fundamental (nas primeiras séries, nos dois ciclos de aprendizado) e do ensino infantil. O projeto tem como objetivo a educação patrimonial, englobando o patrimônio natural regional e nacional. Com o intuito de oferecer aos professores a oportunidade de conhecerem e debaterem sobre o meio em que vivem, foram organizadas saídas de campo para diferentes atrativos turísticos, denominadas aulaspasseio.

Percebe-se que não só as aulas-passeio, mas, também, os roteiros, excursões e saídas de campo são atividades importantes em cursos universitários, Educação Básica e Fundamental, já que é no campo que os alunos podem assimilar ainda mais conhecimento e perceber in loco aspectos ligados às disciplinas integrantes de seus currículos.

Concorda-se, assim, com Scortegagna e Negrão (2005), que afirmam que essas atividades de campo são imprescindíveis e fundamentais para que os professores e alunos observem e interpretem a região que estão visitando, favorecendo um posicionamento perante o saber teórico e a realidade vigente, desmistificando a ciência e construindo um saber mais próximo do seu cotidiano.

Deste modo, a educação ambiental é considerada a via para introduzir, nas escolas, esses conceitos e significados, que poderão ser trabalhados com o auxilio dos meios interpretativos. Portanto, a realização desta pesquisa englobou, em sua metodologia, a participação nas saídas de campo, pesquisas bibliográficas e a aplicação de questionários.

A análise realizada proporcionou uma observação mais aprofundada da importância de uma formação continuada, tendo como objetivo agregar novos conhecimentos que contribuam para a construção de uma consciência conservacionista dos professores e alunos.

\section{O projeto Estudo do Meio}

A Secretaria Municipal de Educação de Ponta Grossa continuamente vem realizando cursos para os professores, no sentido de atender a necessidade de colocar o educando em contato com o meio em que vive e convive, observando diretamente a natureza e o homem, possibilidade contemplada nos Parâmetros Curriculares Nacionais, Terceiro e Quarto Ciclos do Ensino Fundamental (Geografia) (BRASIL, 1997).

Uma dessas iniciativas foi o curso intitulado "Estudo do Meio". Para proporcionar uma formação contínua aos professores, a Secretaria Municipal de Educação elaborou o projeto com o intuito de favorecer, aos professores, a oportunidade de conhecerem e debaterem sobre o meio em que vivem; além disso, foram organizadas aulas-passeio para que os professores disseminassem o conteúdo. O Estudo do Meio está inserido numa metodologia (BRASIL, 1997, p. 62) 
[...] de pesquisa e de organizações de novos conhecimentos, que requer atividades anteriores à visita, levantamento de questões a serem investigadas, seleções de informações, observação de campo, comparação entre os dados levantados e os conhecimentos já organizados por outros pesquisadores, interpretação, enfim, organização de dados e conclusão.

Neste curso, os professores são estimulados a realizar atividades em campo que permitam, ao aluno, estabelecer relações e produzir conhecimentos pela análise da realidade circundante e pelo contato com diferentes tipos de documentos. É um projeto transdisciplinar e que envolveu professores do Ensino Fundamental nas primeiras séries, nos dois ciclos de aprendizado e do ensino infantil.

O Projeto teve também como objetivo a educação patrimonial (histórica e natural), não só da cidade de Ponta Grossa, mas, também, regional e nacional. É ao se realizar uma ação como esta, fora dos muros escolares, que se reforçam os conteúdos vistos em classe e o patrimônio é ainda mais valorizado. As ações iniciaram-se em 2007 e foram realizadas até 2012; e como o interesse demonstrado pelos professores foi grande, os objetivos do estudo foram ampliados, acrescentando-se, também, como meta conhecer lugares mais distantes, mas que tivessem uma ligação patrimonial com a região inicialmente estudada.

O curso oportunizou a visitação de atrativos da Região dos Campos Gerais, do Paraná e de outros estados brasileiros. O início do projeto foi no centro urbano de Ponta Grossa, englobando museus, praças, igrejas e cemitérios. Após, o Estudo do Meio foi realizado nos pontos turísticos mais conhecidos da cidade, como: o Parque Estadual de Vila Velha, Buraco do Padre (no Parque Nacional dos Campos Gerais), Capela Santa Barbara, e os distritos da cidade (Itaiacoca, Guaragi, Periquitos e Uvaia). Outras cidades, como Lapa e Tibagi, também foram visitadas por fazerem parte do contexto histórico-natural da região.

Em outros momentos, os participantes do curso visitaram: o município de São Paulo, Manaus, as cidades históricas de Minas Gerais, Rio de Janeiro e Petrópolis, e o Parque Nacional do Iguaçu, local onde foi aplicado o questionário que será analisado neste trabalho.

Com a realização dessas saídas, o trabalho desenvolvido, posteriormente, com os alunos se torna mais produtivo, pois, com mais conhecimento por parte dos professores, temse uma visão real do lugar, uma maior vivacidade, contribuindo para a construção de uma consciência conservacionista por parte dos professores e dando um suporte para que estes aspectos sejam estudados com os alunos.

Por outro lado, o turismo também integra o conteúdo escolar da Rede Municipal de Ensino de Ponta Grossa. Em 2008, 84 escolas da Rede Municipal receberam kits com material didático sobre o tema, composto de cartilhas para os 9,8 mil alunos das séries determinadas, mapa e DVD com informações turísticas. Através deste Programa, ${ }^{3}$ foi promovido o curso “Turismo Local e Regional”, que contou com a participação de mil professores da rede pública, agora motivados e preparados para trabalharem o conteúdo em sala de aula.

${ }^{3}$ O material foi produzido por meio do Programa de Qualificação Profissional e Social para o Setor Turístico de Ponta Grossa, desenvolvido em parceria entre a Prefeitura e o Ministério do Turismo. 
Assim, em sala de aula, na medida em que os conteúdos são tratados, os professores mostram fotos, vídeos, folders e outros materiais adquiridos durante as saídas, além de relatarem as suas experiências pessoais ao participarem do Curso de Estudo do Meio. Abre-se uma possibilidade de se desenvolver uma visão mais crítica sobre os conteúdos dos livros e materiais didáticos, ao se fazer uma comparação com o material apresentado.

Deste modo, iniciativas como essas são importantes, pois além do conteúdo melhor trabalhado em sala de aula, os professores estarão mais bem preparados para a realização de saídas de campo com seus alunos.

\section{Geodiversidade e roteiros}

Geodiversidade, segundo Stanley (2001 apud NIETO, 2004), é a variedade de ambientes geológicos, fenômenos e processos ativos que dão lugar a paisagens, rochas, minerais, fósseis, solos e outros depósitos superficiais que constituem a estrutura para a vida na Terra. A geodiversidade deve ser o ponto de união entre os homens, a paisagem e a sua cultura, entretanto, tal questão é ainda muito pouco explorada e divulgada. Os aspectos biológicos são muito mais evidenciados que os geológicos - conforme Nieto (2004), isso demonstra que a evolução desses conceitos foi desigual, sobretudo porque o conceito de biodiversidade foi enfocado em diversos trabalhos de grande difusão internacional após a Eco 92, e o de geodiversidade possui pouca divulgação de seus conceitos.

Guillén Mondéjar e Ramo Jiménez (2004) afirmam que a pouca divulgação também é decorrente do fato de que os termos geológicos não estão presentes na linguagem cotidiana e são pouco utilizados por outros profissionais; por isso, é necessário adaptar o vocabulário geológico - conservando o rigor cientifico - à divulgação, conservação e conscientização. Trata-se de tentar criar uma cultura geológica na sociedade de uma forma em geral, fazendo com que os termos mais comuns comecem a fazer parte do vocabulário cotidiano dos cidadãos. Desta forma, a palavra geodiversidade é apropriada, pois possui conotação similar a biodiversidade.

De qualquer modo, é importante que a Terra seja entendida e interpretada como um todo, tanto pelos seus aspectos de biodiversidade, quanto de geodiversidade. E o potencial em relação à realização de roteiros enfocando a geodiversidade pode ser aproveitado, pois, na região dos Campos Gerais, por exemplo, Guimarães et al. (2007, p. 31) ressaltam:

Inúmeros aspectos didáticos podem ser apresentados, exercitados ou debatidos nos Campos Gerais, independente do estilo pedagógico de visita adotado, ou seja, de treinamento, investigativo, contemplativo. Estes locais especiais (ou monumentos geológicos) possuem um imenso potencial educativo e de entretenimento, em especial quando se pretende enfocar questões relacionadas ao uso dos recursos naturais com vistas ao desenvolvimento sustentável.

Contudo, em relação às atividades de campo voltadas para o patrimônio geológico, deve-se levar em consideração a afirmação de Compiani (1991, p. 4), que assevera que 
As atividades de campo, eminentemente práticas e investigativas, devem direcionar o aluno para a aquisição de uma metodologia de campo, que propicie um conhecimento globalizado de uma área de estudo e aquisição de uma visão abrangente da geologia, não devendo consistir em uma mera exposição de processos e fenômenos geológicos.

De qualquer modo, existem também muitas ameaças à geodiversidade. Entre elas, estão o turismo e a visitação desordenada, se realizados sem planejamento adequado. O desafio está no fato de transformar uma ameaça em potencial em uma estratégia de conservação, para tanto, podem ser realizados roteiros enfocando o Patrimônio Natural.

\section{Roteiros turísticos voltados para os aspectos da geodiversidade e os Pontos de Interesse GeoDidáticos (PIGD)}

Roteiros voltados para aspectos geológicos e geomorfológicos são recomendados em áreas que possuem infraestrutura e potencial turístico, pois propiciam um impacto direto no aumento de gastos turísticos, tendo em vista um maior número de produtos disponibilizados para o consumo da demanda. A diversificação de roteiros pode motivar a demanda, sendo uma alternativa econômica para os municípios, beneficiando, também, todo o trade turístico. Valoriza-se mais aquilo que se conhece, portanto, devem-se estimular turistas e a comunidade local para que conheçam os atrativos da região.

Para aproveitar esse potencial, podem ser criados inúmeros roteiros, que podem ser adaptados a diferentes públicos, como: professores e alunos de diversos níveis, geocientistas, turistas e comunidade. Para o planejamento dessas rotas, deve-se: definir um pré-roteiro, realizar a coleta de dados, desenvolver um guia de campo e a simulação do trajeto. Em conjunto, os temas que podem ser trabalhados podem auxiliar na prestação de atividades interpretativas e educativas com a mais alta qualidade (MOREIRA; BIGARELLA, 2010).

Para selecionar quais os locais que podem ser visitados, baseando-se na metodologia de Corvea et al. (2004), são propostos Pontos de Interesse GeoDidáticos (PIGD), a serem utilizados, sobretudo, por professores em saídas de campo. Esses pontos são compostos pelo conjunto de recursos naturais cuja singularidade, qualidades e propriedades facilitam, com um enfoque pedagógico, o conhecimento in situ de seus valores científicos.

No caso da Comunidade de Madrid, a determinação de pontos de interesse didático permitiu a sua classificação por áreas especificas de conhecimento, sendo uma ferramenta pedagógica, flexível e eficaz, cuja eficácia depende de um esforço adicional por parte dos professores, que devem conhecer a região e estar em constante atualização (CORVEA et al., 2004).

Adaptando essa metodologia aos aspectos geológicos, são propostos os PIGD, no sentido de facilitar o reconhecimento da finalidade dos pontos, relacionando-os aos aspectos geológicos (MOREIRA, 2008).

No caso do Parque Nacional do Iguaçu (PNI), os critérios utilizados para a escolha basearam-se na adequação dos Pontos para a sua utilização em atividades educativas e interpretativas, onde foram verificadas, também, a sua representatividade, visibilidade, facilidade e 
Moreira, J. C.; Pinto, M. C. T.

possibilidade de acesso, sendo locais onde as características geológicas podem ser mais bem explicadas e compreendidas (MOREIRA; BIGARELLA, 2009).

\section{Resultados}

\section{A participação em atividades do curso, sob a ótica do professor}

O curso oferecido em Ponta Grossa, intitulado Estudo do Meio, abre um caminho para a formação continuada dos professores. $\mathrm{Na}$ ótica do professor, o curso é de grande importância, pois o mesmo deve sempre estar se atualizando e se qualificando para que o ensino oferecido seja da melhor qualidade possível. A oportunidade de participação num curso como este traz, ao cursista, novos conhecimentos, uma nova visão sobre os assuntos por ele trabalhados. Ao conhecer esses lugares que são trabalhados, com o auxilio de textos e livros didáticos, transforma-se a maneira como esses assuntos são estudados, melhorando ainda mais esse repasse de conhecimentos.

Como participantes do curso, foi verificado que os professores notam que suas verdades, já assimiladas por anos de profissão, tornam-se pequenas em face do mundo de novas informações que se juntam aos seus conhecimentos, através das aulas-passeio realizadas.

São projetos como esse que ajudam no desenvolvimento da escola como um todo, pois auxiliam na mudança da visão dos professores, ao tornarem mais claro que, numa saída de campo bem estruturada e planejada, o conteúdo trabalhado será vivenciado pelos alunos de uma maneira que eles jamais esquecerão.

\section{Análises dos questionários aplicados aos professores participantes do curso de Estudo do Meio}

No sentido de avaliar o interesse e a possibilidade da utilização dos PIGDs, pelos professores, em saídas de campo a serem realizadas com seus alunos, em junho de 2008 foi

realizado o acompanhamento de um grupo de cinquenta professores do Curso de Estudo do Meio, a uma saída de campo no Parque Nacional do Iguaçu, em Foz do Iguaçu (Figura 1).

Durante essa saída, foram utilizados alguns dos PIGDs. Após a realização da visita, foi realizada uma palestra, onde foram explicados: os objetivos desta pesquisa, maiores explanações sobre os PIGDs, os critérios de seleção e as possibilidades da sua utilização em atividades interpretativas em duas Unidades de Conservação (UC), o Parque Nacional do Iguaçu (PNI) e o Parque Estadual de Vila Velha (PEVV), UC previamente visitada (Figura 2).

No total, 48 professores responderam a um questionário e os dados são apresentados no Gráfico 1. 
O projeto Estudo do Meio em Ponta Grossa...

Figura 1. Grupo de professores do curso Estudo do Meio no Parque Nacional do Iguaçu, PR.

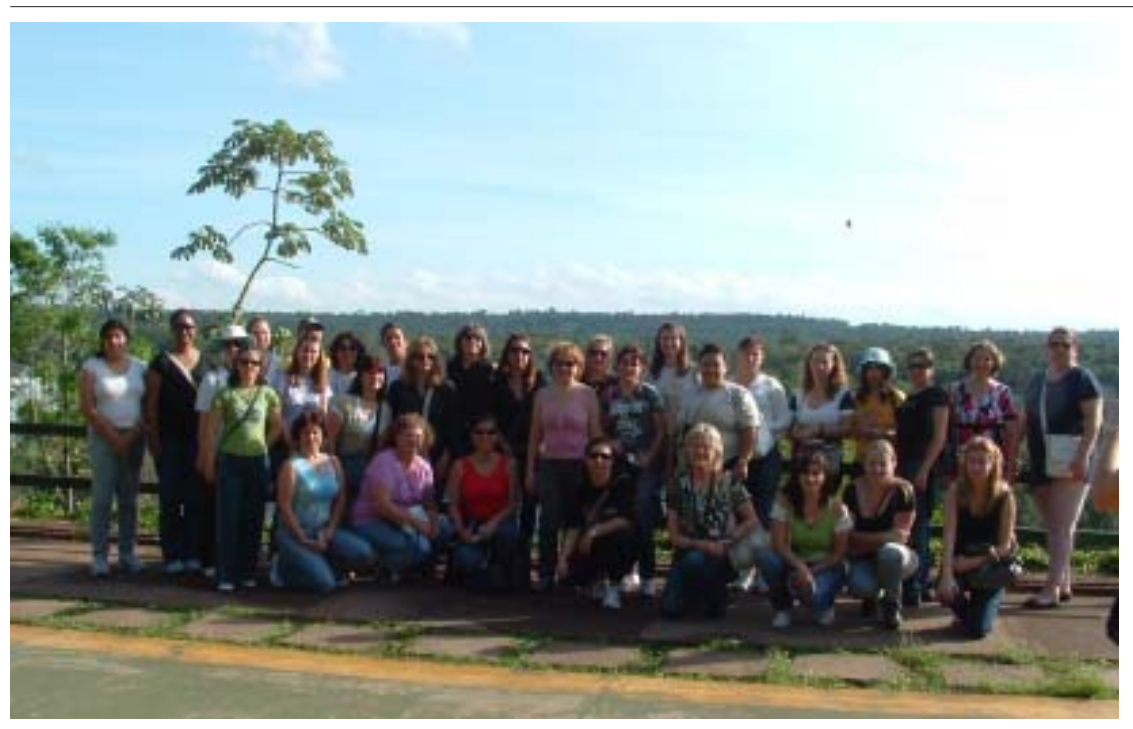

Fonte: elaborado pelas autoras.

Figura 2. Parque Estadual de Vila Velha (PEVV), localizado em Ponta Grossa, PR (unidade de conservação visitada pelos professores integrantes do Curso de Estudo do Meio em 2008)

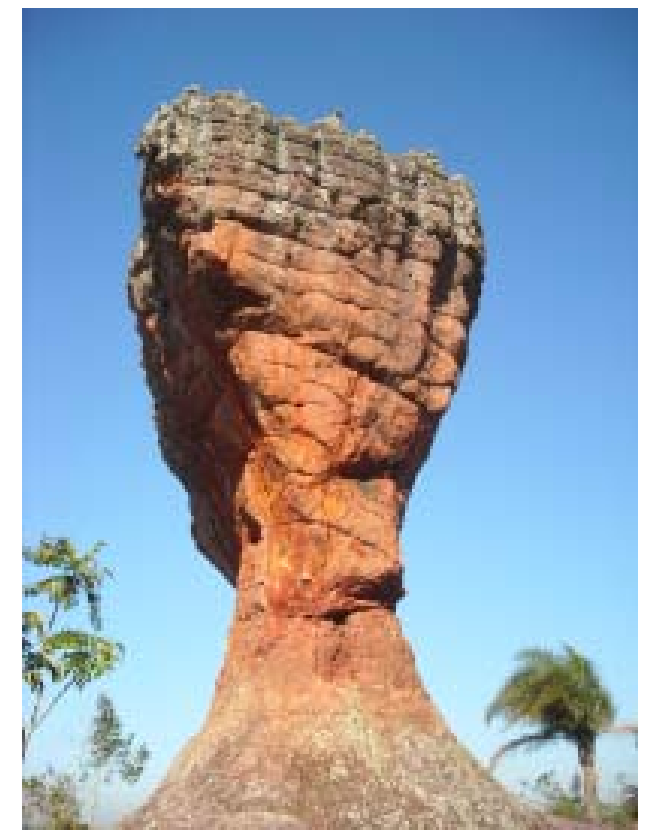

Fonte: elaborado pelas autoras. 
Moreira, J. C.; Pinto, M. C. T.

Gráfico 1. Séries em que são ministradas aulas pelos professores participantes do curso Estudo do Meio.

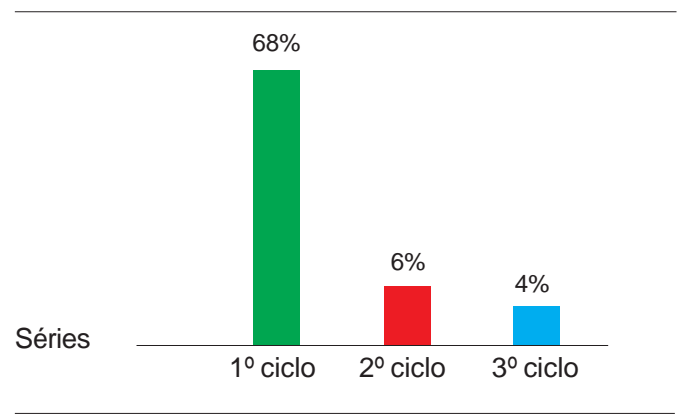

Fonte: elaborado pelas autoras.

O município de Ponta Grossa possui Sistema Próprio de Ensino ${ }^{4}$ desde o final do ano de 2004, o qual é dividido em dois ciclos. O $1^{\circ}$ ciclo é composto de três séries, o $2^{\circ}$ ciclo é composto de duas séries. A grande maioria dos professores que respondeu ao questionário ministra aulas no $1^{\circ}$ Ciclo (67\%), seguida dos professores que ministram aulas no $2^{\circ}$ Ciclo $(28 \%)$. Na categoria "Outros" estão englobados os casos referentes a coordenadoras pedagógicas, uma funcionária da Secretaria Municipal de Educação e uma professora que também ministra aulas na Educação de Jovens e Adultos (Gráfico 1).

Quando perguntados a respeito dos PIGDs, e se os mesmos auxiliaram na compreensão da geodiversidade do PNI (Gráfico 2), somente dois professores (4\%) responderam que

Gráfico 2. Compreensão da geodiversidade com o auxílio dos Pontos de Interesse Geodidáticos (PIGDs).

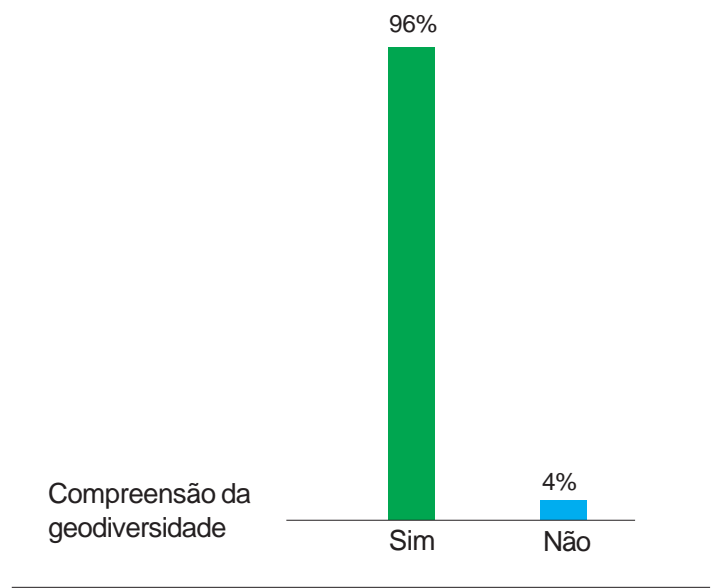

Fonte: elaborado pelas autoras.

${ }^{4} \mathrm{O}$ Ensino Fundamental de nove anos promove a consolidação do processo de aquisição do código escrito e desenvolve as habilidades e competências necessárias da Língua Portuguesa, garantindo um tempo maior de aprendizagem. 
não. Ou seja, a maioria dos professores, com o auxílio dos PIGDs utilizados durante a saída de campo, conseguiu compreender melhor os aspectos geológicos e geomorfológicos do local visitado, sendo esta uma ferramenta didática que auxilia na compreensão do ambiente.

Nas duas questões seguintes, $100 \%$ dos entrevistados responderam 'sim' às perguntas efetuadas. Ou seja, todos os professores consideram a possibilidade de usar os PIGDs em suas saídas de campo, o que só vem a justificar ainda mais a criação dos mesmos, visto que a totalidade dos entrevistados também considera que a utilização dos PIGDs irá facilitar seus trabalhos a serem realizados em campo.

Além disso, após explicações sobre o geoturismo e o potencial do PEVV e PNI, $100 \%$ dos entrevistados acreditam que o geoturismo pode ser praticado na região.

Gráfico 3. Número de professores que acreditam ser importante a participação em outros roteiros.

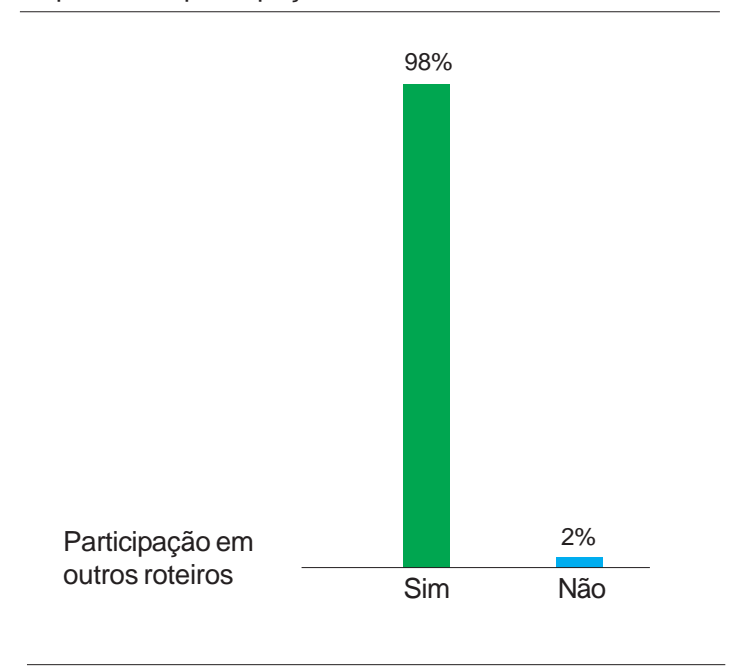

Fonte: elaborado pelas autoras.

No caso da participação em outros roteiros, enfocando aspectos geológicos e geomorfológicos que poderiam existir na região, somente uma professora não participaria (Gráfico 3). Tal avaliação pode ter se dado pelo fato de que esta professora considera suficiente o Parque Estadual de Vila Velha como UC para a realização de saídas de campo, não se interessando por outros possíveis roteiros pelo Estado. De qualquer modo, a grande maioria das entrevistadas participaria de outros roteiros, o que denota o potencial que a região possui não somente para o geoturismo mas, também, para a realização de atividades educativas e a interpretação do ambiente geológico. 
Gráfico 4. Outros meios interpretativos sugeridos pelas professoras.

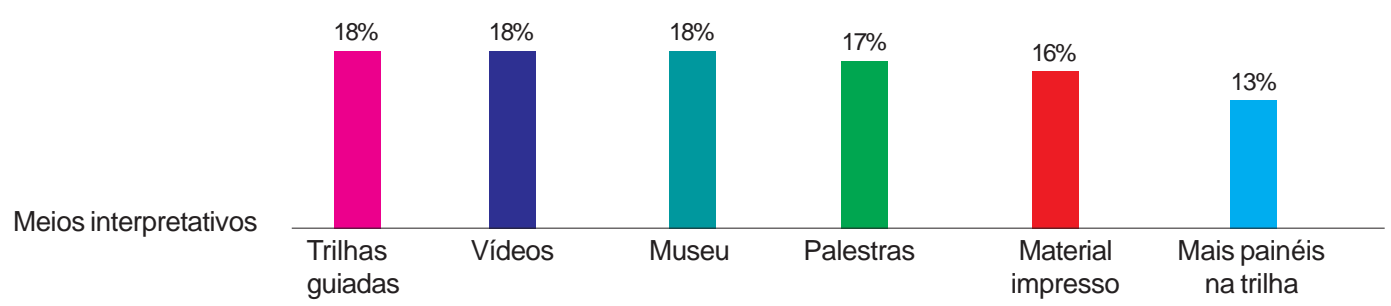

Fonte: elaborado pelas autoras.

E quando perguntadas a respeito de outros meios interpretativos que poderiam ser utilizados, e que acreditam serem os mais eficazes para a adequada interpretação do ambiente, as entrevistadas tiveram opiniões muito parecidas, visto que mais de uma alternativa poderia ser escolhida. A maioria considerou que os vídeos, museus e trilhas guiadas (18\%) são os mais eficazes, seguidos das palestras (17\%), material impresso (16\%) e mais painéis nas trilhas (13\%).

Desta forma, com a utilização dos PIGDs, pelos professores, condutores e visitantes, com interesse específico, como os geoturistas, as informações estarão organizadas, de modo que, em cada ponto, pode-se enfocar a atenção da audiência nos detalhes que estão sendo interpretados, explicando o que é mais significativo, tendo, assim, a oportunidade de ligar a explicação ao tema geológico e geomorfológico.

\section{Propostas de Geoeducação}

O processo de ensino-aprendizagem possui papel fundamental em todos os níveis educativos, e, neste caso, os PIGDs podem auxiliar os professores na elaboração de suas saídas de campo que englobem aspectos da geodiversidade.

Tais saídas, se bem organizadas, poderão auxiliar a transmitir conhecimentos que sejam não somente memorizados, e sim inesquecíveis. Dessa maneira, os conhecimentos adquiridos serão utilizados durante a vida escolar dos alunos e servirão de embasamento para uma melhor compreensão da geodiversidade em sua volta.

E para auxiliar numa maior aproximação entre os aspectos geológicos e as atividades educativas, sobretudo entre as crianças, pode-se utilizar um símbolo como marca. Em Ponta Grossa, no caso do Parque Estadual de Vila Velha, a Taça pode ser esse símbolo. Tal símbolo pode também integrar os meios interpretativos, como os painéis, folders, jogos, livros para colorir, entre outros.

Quando tratamos o conhecimento de maneira lúdica e interativa com os alunos, a aprendizagem implica uma significativa aquisição de informações, facilitando a formação do aluno. Portanto, uma das atividades sugeridas para $1^{\circ}$ e $2^{\circ}$ Ciclos são os livros para colorir, que 
O projeto Estudo do Meio em Ponta Grossa...

podem conter símbolos, desenhos representando monumentos geológicos, elementos da biodiversidade, entre outros, em conjunto com a abordagem dos temas em saídas a campo.

Juntamente com os outros meios interpretativos que podem ser utilizados em atividades educativas, são propostas atividades em cartilhas ilustradas, para serem realizadas dentro e fora da sala de aula. Para tanto, os professores devem planejar a saída de campo com o apoio de um check-list de Saída de Campo, e selecionar quais os PIGDs que serão trabalhados. Algumas dessas atividades propostas são:

a) Dentro da sala de aula:

- Apresentação da atividade que será realizada e dos pontos selecionados, utilizando transparências, data-show, fotos, material impresso, entre outros, e a realização de atividades em equipe, sobre o local selecionado.

b) Atividades em campo:

- Identificação e apresentação dos PIGDs selecionados;

- Realização de trilhas interpretativas, roteiros ou excursões.

c) Após as atividades em campo:

- Realização de atividades para verificar o feedback e para que os alunos compreendam melhor todo o conteúdo trabalhado;

- Elaboração de relatório sobre a atividade desenvolvida, contendo os resultados obtidos, dificuldades e perspectivas de reedição, divulgando-o entre os demais professores interessados.

Mas, para que as atividades sejam realizadas, é importante que sejam divulgadas para as escolas, o que poderia ser feito através de um site onde os professores poderiam realizar o download de arquivos relacionados à realização das atividades e sobre os PIGDs, diretamente para seus computadores. Além disso, essas atividades também poderiam ser adaptadas para a sua realização com universitários, comunidade e visitantes em geral.

Outras estratégias de geoeducação que podem auxiliar na interpretação do ambiente são os cursos e seminários com enfoque geológico, que podem ser oferecidos aos professores e o público em geral, e minicursos sobre a geodiversidade e peculiaridades geológicas da região. Tais atividades podem ser de curta duração (uma manhã ou tarde, preferencialmente aos finais de semana).

\section{Considerações finais}

A comunidade local, professores e visitantes devem reconhecer a importância da diversidade natural no que diz respeito ao seu patrimônio, que não é somente biológico, mas geológico também. Para tanto, devem ser oferecidas atividades que interpretem esse patrimônio.

Neste sentido, o município brasileiro de Ponta Grossa desenvolveu, entre 2007 e 2012, o Projeto Estudo do Meio, destinado aos professores do Ensino Público Fundamental e do ensino infantil, com o objetivo de realizar a educação patrimonial, englobando o patrimô- 
Moreira, J. C.; Pinto, M. C. T.

nio natural regional e nacional. Projetos como esse servem como um exemplo, pois é conhecendo e debatendo sobre o meio em que vive que o professor pode incrementar ainda mais seu processo de ensino e aprendizagem.

De qualquer modo, é importante que a Terra seja entendida e interpretada como um todo, tanto pelos seus aspectos de biodiversidade, quanto de geodiversidade. E o potencial em relação à realização de roteiros enfocando a geodiversidade pode ser aproveitado.

Deste modo, a pesquisa realizada demonstrou que há o interesse, por parte dos professores, na realização de roteiros turístico-pedagógicos envolvendo tais aspectos da geodiversidade. Como resultado, foi observada a importância de uma formação continuada, tendo como objetivo agregar novos conhecimentos que contribuam para a construção de uma consciência conservacionista não só dos professores, mas, também, dos alunos.

\section{Referências}

BRASIL. Ministério da Educação. Parâmetros curriculares nacionais. Brasília: MEC: SEMTEC, 1997.

COMPIANI, M. A relevância das atividades de campo no ensino da geologia na formação de professores de ciências. Campinas: Unicamp, 1991. (Cadernos do IG).

CORVEA, J. L. et al. Los puntos de interes didactico: uma alternativa metodológica para el conocimiento del patrimônio natural. In: GUILLÉN MONDÉJAR, F.; RAMO JIMÉNEZ, A. (Ed.). El patrimonio geológico: cultura, turismo y medio ambiente - actas de la $\mathrm{V}$ Reunión de la Comisión de Patrimônio Geológico de la Sociedad Geológica de España. Murcia: Universidad de Murcia, 2004. p. 177-183.

GUILLÉN MONDÉJAR, G; RAMO JIMÉNEZ, A. Manifiesto por la conservación, divulgación y uso del patrimonio geológico y la geodiversidad de la región de Murcia. In: . (Ed.). El patrimonio geológico: cultura, turismo y medio ambiente - actas de la V Reunión de la Comisión de Patrimônio Geológico de la Sociedad Geológica de España. Murcia: Universidad de Murcia, 2004. p. 343-348.

GUIMARÃES, G. B. et al. Geologia dos Campos Gerais. In: MELO, M. S.; MORO, R. S.; GUIMARÃES, G. B. Patrimônio natural dos Campos Gerais. Ponta Grossa: Editora da UEPG, 2007. p. 23-32.

MOREIRA, J. C. Patrimônio geológico em unidades de conservação: atividades interpretativas, educativas e geoturísticas. 2008. 429 f. Tese (Doutoramento em Geografia) Centro de Filosofia e Ciências Humanas, Universidade Federal de Santa Catarina, Florianópolis, 2008.

MOREIRA, J. C.; BIGARELLA, J. J. Geotouristic tours and excursions in Paraná (Brazil): viability and proposals. In: GLOBAL GEOTOURISM CONFERENCE, 2., 2010, Miri, Malaysia. Conference Proceedings... Miri: Sarawak Tourism Board, 2010. v. 1, p. 23-25. 
O projeto Estudo do Meio em Ponta Grossa...

O Parque Nacional do Iguaçu e atividades ligadas ao geoturismo: em busca de uma maior valorização do patrimônio geológico. In: CONGRESSO BRASILEIRO DE UNIDADES DE CONSERVAÇÃO, 4., 2009, Curitiba. Anais... Curitiba: Wave Media, 2009. v. 1. 1 CD-ROM.

NIETO, L. M. Aproximacion al concepto de geodiversidade. In: GUILLÉN MONDÉJAR, F.; RAMO JIMÉNEZ, A. (Ed.). El patrimonio geológico: cultura, turismo y medio ambiente - actas de la V Reunión de la Comisión de Patrimônio Geológico de la Sociedad Geológica de España. Murcia: Universidad de Murcia, 2004. p. 117-123.

SCORTEGAGNA, A.; NEGRÃO, O. B. M. Trabalhos de campo na disciplina de geologia introdutória: a saída autônoma e seu papel didático. Terrae Didactica, Campinas, v. 1, n. 1, p. 36-43, 2005. Disponível em: <http://www.ige.unicamp.br/terraedidatica/v1/pdf-v1/ p036-043_scortegagna.pdf >. Acesso em: 07 jul. 2007.

Artigo recebido em 12/01/13. Aceito em 18/10/13. 